"Supporting Information"

\title{
Electrically Controlled Lasing in Supercooled Liquid Crystal Blue Phase I Microdroplets
}

Gia Petriashvili, ${ }^{1}$ Ridha Hamdi, ${ }^{2,3 *}$ Andro Chanishvili, ${ }^{1}$ Tsisana Zurabishvili, ${ }^{1}$ Ketevan Chubinidze ${ }^{1}$, and Nino Ponjavidze ${ }^{1}$

${ }^{1} \mathrm{~V}$. Chavchanidze Institute of Cybernetics of the Georgian Technical University, Z.Anjaparidze 5, Tbilisi, 0186, Georgia

${ }^{2}$ Department of Physics, College of Science, Imam Abdulrahman Bin Faisal University, P.O. Box 1982, 31441 City Dammam, Saudi Arabia

${ }^{3}$ Basic and Applied Scientific Research Center, Imam Abdulrahman Bin Faisal University, P.O. Box 1982, 31441 Dammam, Saudi Arabia

*rhamdi@iau.edu.sa 


\section{Nematic Liquid crystal E7:}

It is a eutectic mixture of four different nematogens; $(\mathrm{C} 18 \mathrm{H} 19 \mathrm{~N}, \mathrm{C} 20 \mathrm{H} 23 \mathrm{~N}, \mathrm{C} 21 \mathrm{H} 25 \mathrm{NO}$ and $\mathrm{C} 24 \mathrm{H} 23 \mathrm{~N})$
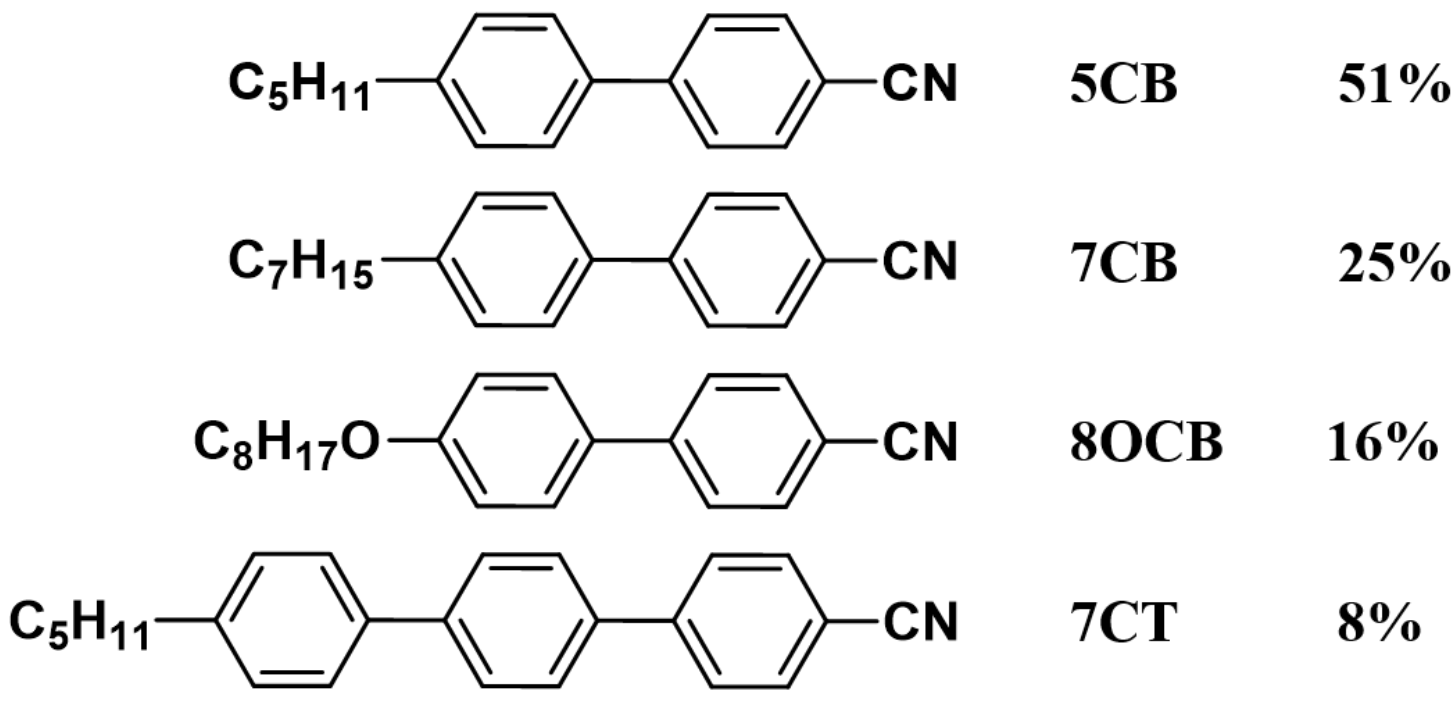

Figure S1: molecular structure of E7

\section{CB-15:}

It is a right-handed cholesteric liquid crystal (CLC), with short pitch and low isotopic-CLC temperature transition; (S)-4'-(2-Methylbutyl)-[1,1'-biphenyl]-4-carbonitrile; C18H19N

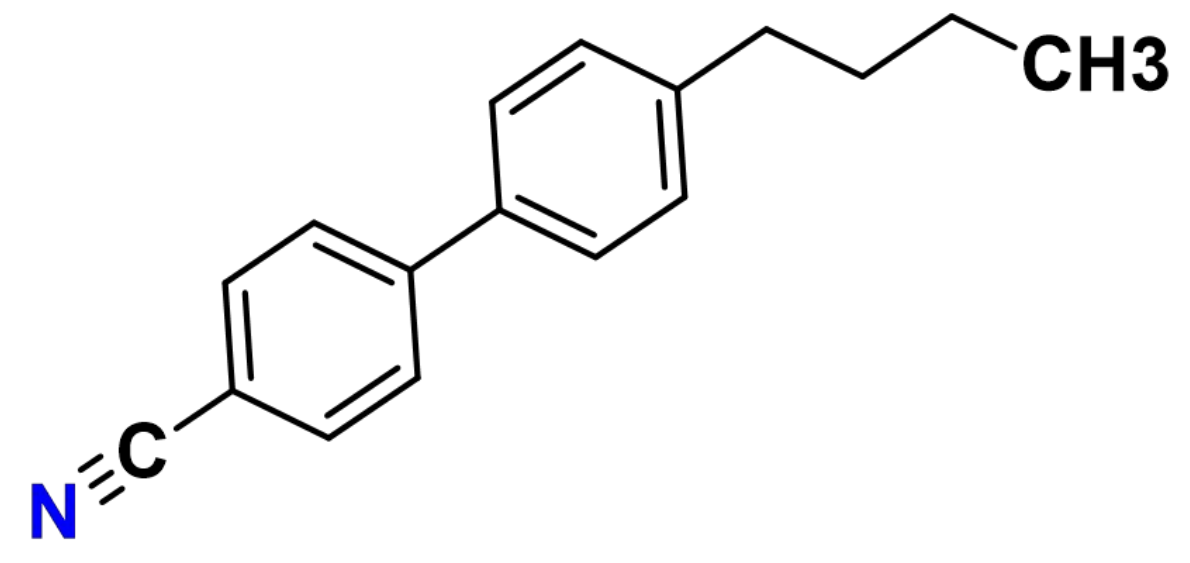

Figure S2: molecular structure of CB-15

\section{MLC-6248:}

It is a non-liquid crystal. It is right-handed optically active dopant; [4(S)-[trans(trans)]]-1,3Difluoro-2-[(1-methylheptyl)oxy]-5-(4'-propyl[1,1'-bicyclohexyl]-4-yl)benzene; C29H46F2O 


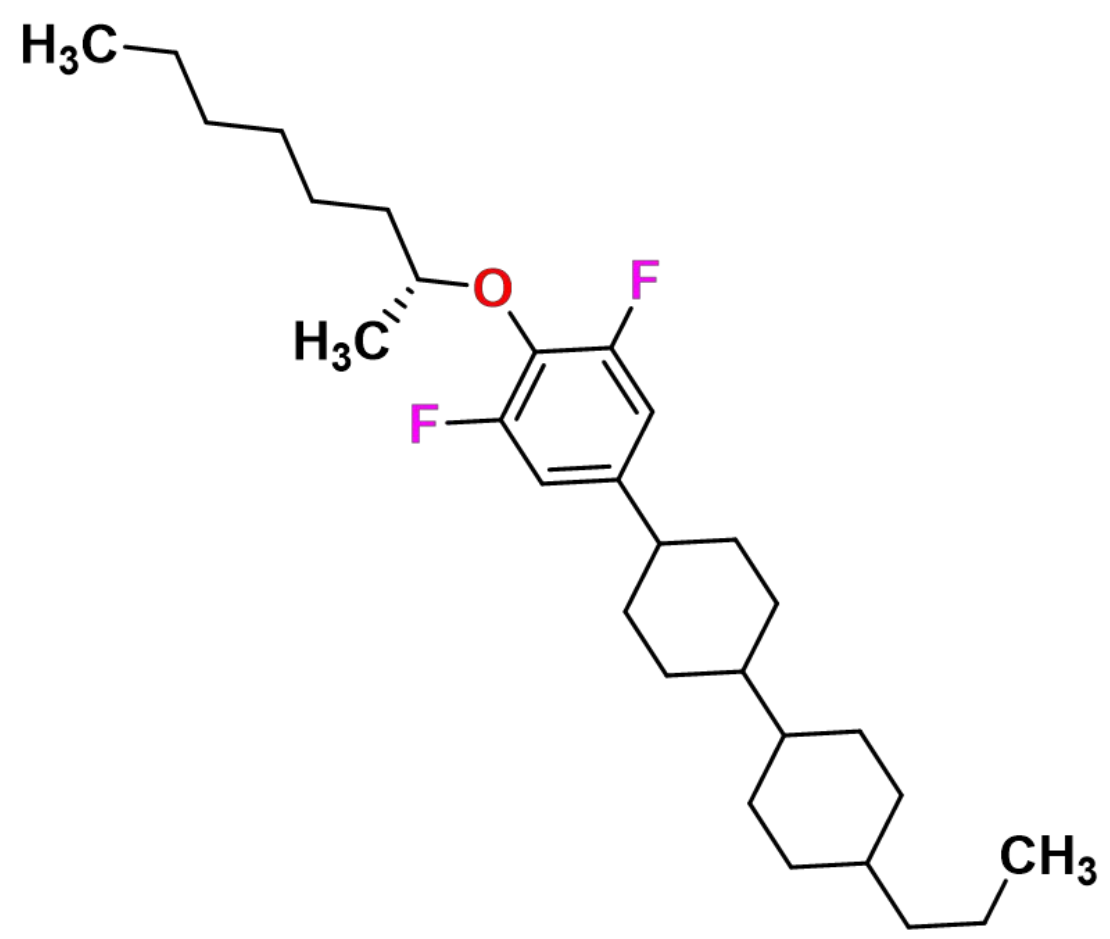

Figure S3: molecular structure of MLC-6248

\section{UVITEX:}

It is a dye; (2,5 -2,5-thiophenediylbis(5-tert-butyl-1,3-benzoxazole); C26H26N2O2S

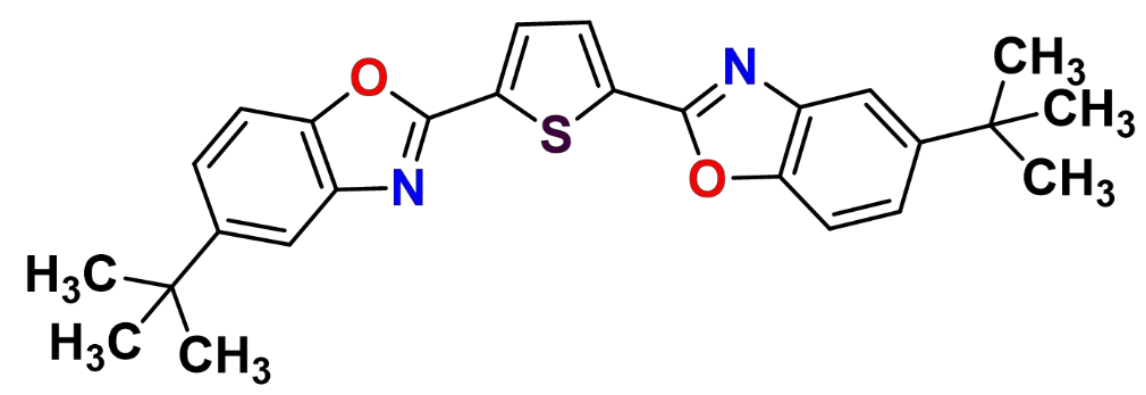

Figure S4: molecular structure of UVTEX

\section{DCM:}

It is a dye; (4-Dicyanomethylene-2-methyl-6-(p-dimethylaminostyryl)-4H-pyran; C19H17N3O 


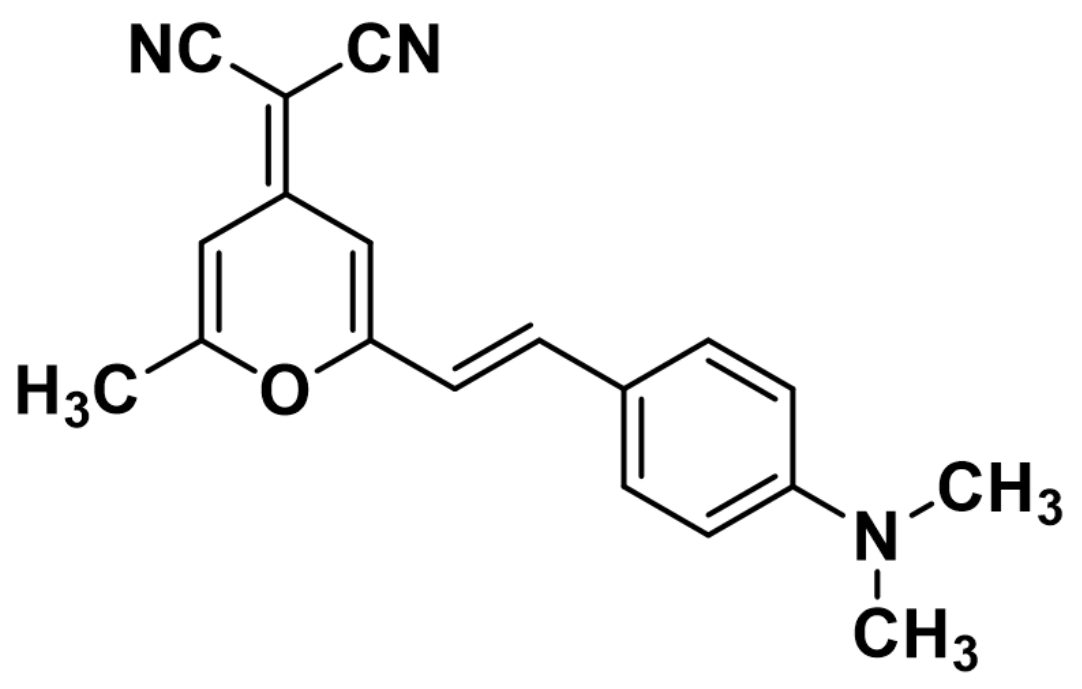

Figure S5: molecular structure of DCM 